\title{
Multicentric reticulohistiocytosis: a case report
}

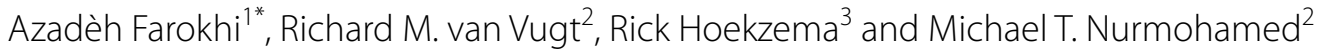

\begin{abstract}
Background: Multicentric reticulohistiocytosis is a rare form of non-langerhans cell histiocytosis presenting with skin changes and erosive arthritis. Infiltration of histiocytes and multinucleated giant cells are typical histological findings and confirm the diagnosis.

Case presentation: This case report describes a newly diagnosed case of multicentric reticulohistiocytosis in a healthy 26-year-old female originally from the Philippines. Eruption of papules and nodules on the hands and pain in multiple joints were the main complaints at the initial presentation. Radiographical findings of erosions in the small hand and feet joints were impressive. Initial histological findings did not match the clinical image, although later the clinical diagnosis was supported by histological findings in additional biopsies.
\end{abstract}

Conclusions: Although initial histological findings did not match the clinical image, additional biopsies were valuable to confirm the diagnosis.

Keywords: Multicentric reticulohistiocytosis, Non-langerhans cell histiocytosis, Histiocytosis

\section{Background}

Multicentric reticulohistiocytosis (MRH) is a form of non-langerhans cell histiocytosis which is rarely diagnosed. The most common presentation includes skin changes, mostly papulo-nodular eruptions in the upper extremities, and erosive arthritis. Internal organs are sometimes affected as well, which is evident from reports of pleural and pericardial effusion in patients with this disease [1]. Goltz and Laymon proposed the name multicentric reticulohistiocytosis in 1954 because of the multifocal origin and systemic nature of the disease [2]. Histologically, an infiltration of histiocytes and multinucleated giant cells can be found in lesions [3]. The prevalence of multicentric reticulohistiocytosis is not exactly known, approximately 300 cases have been reported in medical literature. A significant number of cases were associated with malignant disease, such as breast cancer, melanoma, lung cancer and cancer of colonic origin [1, 3]. The treatment of multicentric reticulohistiocytosis

\footnotetext{
*Correspondence: a.farokhi@vumc.nl

${ }^{1}$ VU University Medical Center, De Boelelaan 1117, 1081 HV Amsterdam, The Netherlands

Full list of author information is available at the end of the article
}

is not well protocolled and mostly empirical due to the unknown etiology [4]. The course and outcome of multicentric reticulohistiocytosis are unpredictable and although the disease is often self-limiting, joint deformities remain as non-denying remnants of the disease [3]. Due to the destructive nature of the arthritis in about $45 \%$ of the cases, early recognition of multicentric reticulohistiocytosis is essential and awareness among clinicians desired.

\section{Case presentation}

We present a case of a healthy 26-year-old female of Philippine origin who presented to our outpatient clinic with a progressive eruption of cutaneous papules and nodules. Her medical history reported nodules/papules on the hands 7 years before, for which she successfully received prednisone in the Philippines with only a few residual lesions. Recently, over a course of 2 months, she noticed an increasing number of cutaneous nodules and papules; starting on her hands subsequently spreading to her wrists and forearms. Pain arose from these nodules when bumped onto a surface. Simultaneously, our patient suffered from pain and stiffness in hands, feet, elbows, shoulders and knees. Over these 2 months she 
felt increasingly tired. Our patient also reported a red, warm rash covering her cheeks at the start of the symptoms, which had subsided by the time of investigation. There were no signs of systemic illness, inflammation or preceding infections.

Three weeks before our initial investigation she had tried prednisone $30 \mathrm{mg}$ for 3 days. Since then, she reported the occurrence of new skin lesions, a swollen face and palpitations. At the time of investigation she only sporadically used NSAIDs to control the pain.

On clinical examination numerous firm, either reddish-brown or skin-colored papules and nodules were seen and felt mainly on the hands and forearms, varying in size from 0.5 to $1 \mathrm{~cm}$ (Fig. 1). In addition, papules were found in pre-existing scars on the left shoulder and both knees. Apart from these papules and nodules, a few patches of grouped, flat, red/brown papules were seen on the inner side of the upper arms, on the hips, thighs and neck (Fig. 2).

At the time of examination, pain was present on palpitation of many of the small hand joints [distal interphalangeal (DIP), proximal interphalangeal (PIP) and metacarpophalangeal (MCP)], wrists, elbows and knees. Arthritis was present in several PIPs and in the wrist. Furthermore, her face appeared to be swollen. There was no lymphadenopathy. Laboratory examination revealed a normal level of ESR (erythrocyte sedimentation rate), negative antinuclear (ANA) and anti-cyclic citrullinated peptide (anti-CCP) antibodies and the IgM Rheumatoid factor was borderline positive $(6.3, \mathrm{ref}<5.0 \mathrm{IU} / \mathrm{ml})$.

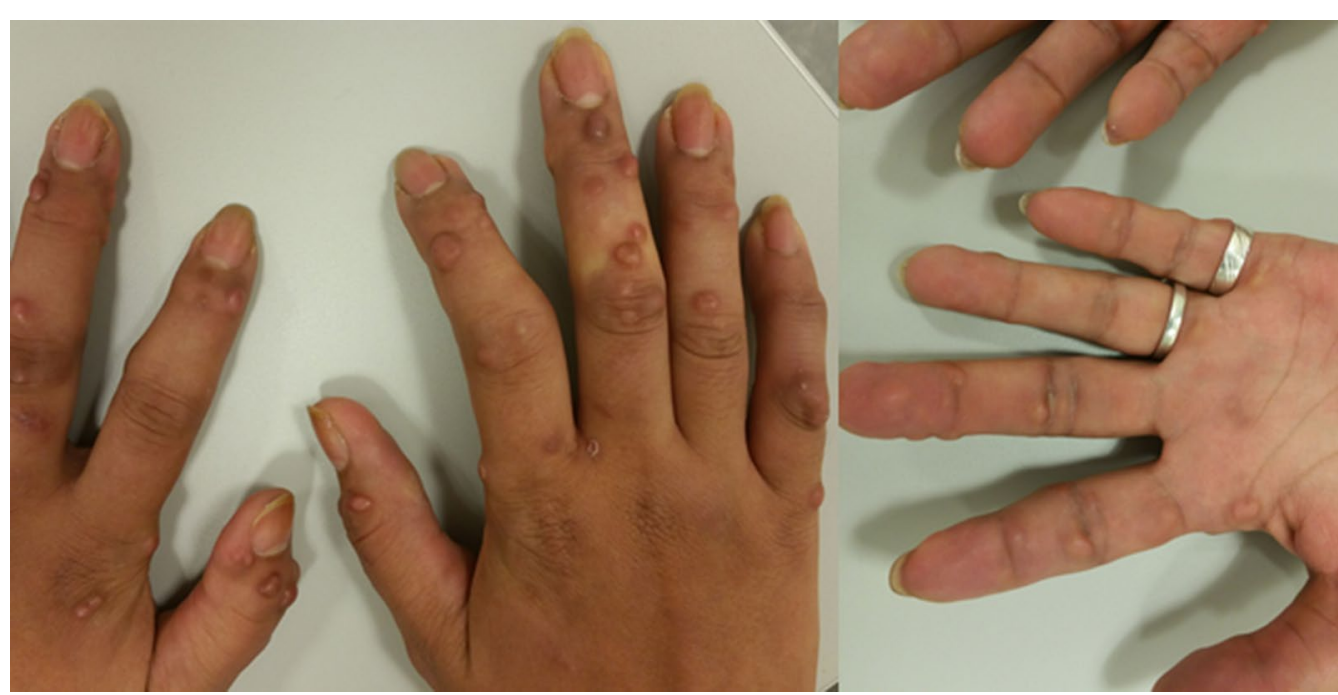

Fig. 1 Firm nodules and papules $(0.5-1.0 \mathrm{~cm})$ on the hands at time of presentation

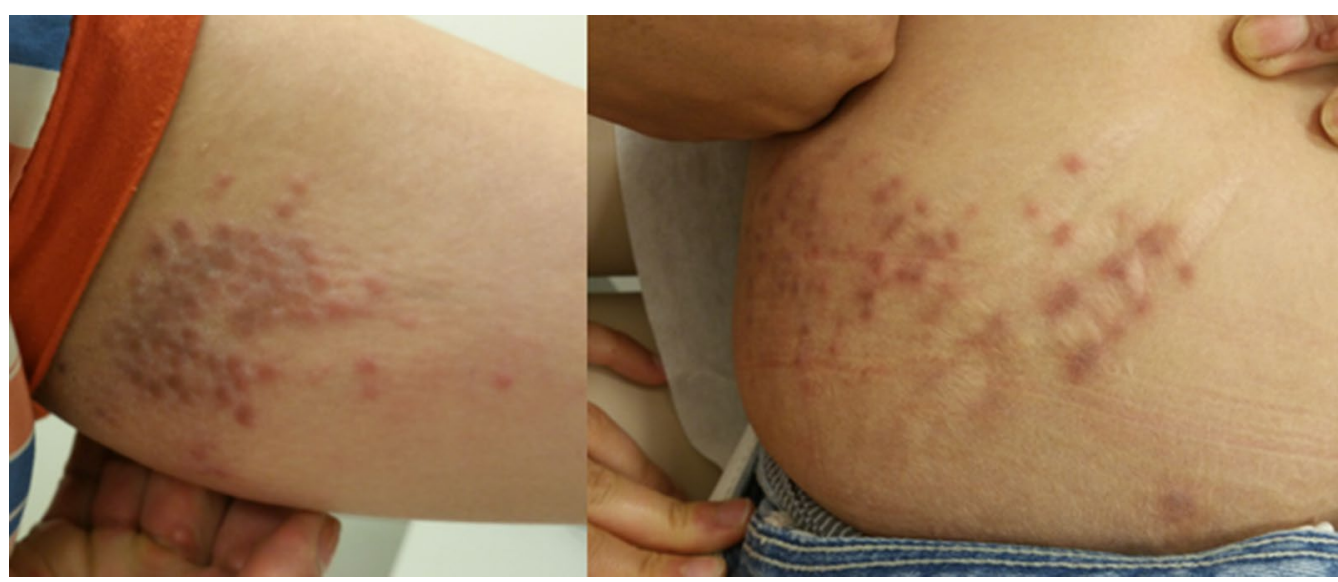

Fig. 2 Patches of grouped, flat, red/brown papules which arose after use of prednisone, $30 \mathrm{mg}$ for 3 days 


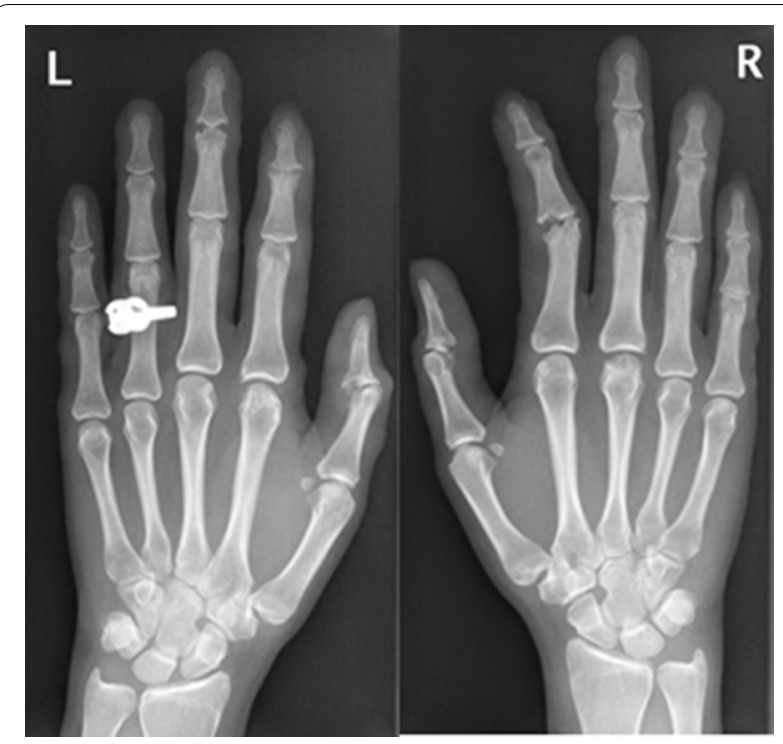

Fig. 3 Radiographs of the hands, showing impressive erosions and destruction of small joints

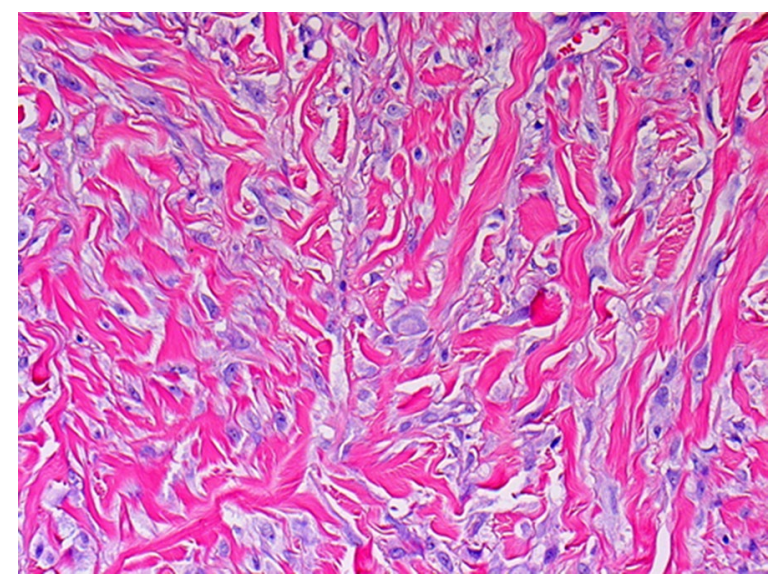

Fig. 4 Numerous large histiocytes with sharply delineated nuclear membranes and prominent nucleoli are scattered through the dermal collagen. In the center a multinucleate giant cell is present (hematoxylin and eosin, original magnification $\times 200$ ). Most of the histiocytes stained positive for CD68, whereas immunostaining for CD1a (Langerhans cells) was negative (not shown)
Other serum and urine laboratory tests were unremarkable. Radiographs of the hands and feet, however, showed impressive erosions and destruction of many small joints (Fig. 3) and a radiograph of the lungs showed a closed right pleural sinus.

Punch biopsies were taken from the nodules on the hands and from the plaque on the upper arm. Initially, a histological pattern of dermal scarring/fibrosis was found, without histological features of multicentric reticulohistiocytosis. However, additional biopsies showed CD-68 positive macrophages and eosinophilic granulocytes between the collagen fibers in the dermis, in agreement with a form of non-Langerhans histiocytosis (Fig. 4).

The PET/CT scan revealed FDG-avidity in the muscles of the thighs and buttocks, the corresponding points were painful to the touch according to our patient. Also, painful joints showed slightly more uptake when compared to the representative opposite joints.

Because of the reported association with underlying malignancies [3-5], additional investigations were performed. Malignancy became very unlikely after laboratory tests, ultrasound of the abdomen, mammography, $\mathrm{PET} / \mathrm{CT}$ scan and an additional MRI scan for further imaging of suspicious lesions in one of the mammae.

The initiated therapy consisted of prednisone, methotrexate and risedronate together with folic acid and calcium/vitamin D. This choice was based on an overview of different treatment regimens and outcomes published recently [1]. Prednisone was started on $30 \mathrm{mg}$ and tapered to $7.5 \mathrm{mg}$ in 9 weeks. Methotrexate was introduced to a final dosage of $25 \mathrm{mg} /$ week over 8 weeks. Risedronate was chosen as bisphosphonates are considered to be of additional benefit in the treatment of multicentric reticulohistiocytosis [6]. Since the patient is in her reproductive age, we chose the bisphosphonate with the least implications for future pregnancy.

After 8 weeks of therapy, the joint pain had subsided and our patient was better able to move without pain. The skin lesions, however, persisted over these first 2 months of therapy. A few months later, arthritis of the right elbow was identified but the skin lesions seemed to improve and there were less complaints of itchiness.

\section{Discussion and conclusions}

This case report was written to inform specialists about the clinical image of multicentric reticulohistiocytosis and the initial nonspecific histological findings. Since knowledge about the course of the disease and the resulting disabilities is limited, awareness is warranted among clinicians and experience should be shared in order to improve clinical care for patients with multicentric reticulohistiocytosis.

\section{Abbreviations \\ $\mathrm{MRH}$ : multicentric reticulohistiocytosis.}

\section{Authors' contributions}

AF had initial contact with the patient and took care of follow up of the patient and wrote the case report. MN supervised of AF at initial contact and during follow up, also first corrector for article text. RV guided in diagnosis and raised awareness of disease, he also commented on article text. $\mathrm{RH}$ : parallel dermatological care for patient, gave direction and confirmation of diagnosis 
and commented on article text. All authors read and approved the final manuscript.

\section{Author details}

${ }^{1}$ VU University Medical Center, De Boelelaan 1117, 1081 HV Amsterdam, The Netherlands. ${ }^{2}$ Rheumatology Department, VUMC Amsterdam, De Boelelaan 1117, 1081 HV Amsterdam, The Netherlands. ${ }^{3}$ Dermatology Department, VUMC Amsterdam, De Boelelaan 1117, 1081 HV Amsterdam, The Netherlands.

\section{Acknowledgements}

Not applicable.

\section{Competing interests}

The authors declare that they have no competing interests.

\section{Availability of data and materials}

All data generated or analysed during this study are included in this published article.

\section{Consent for publication}

The patient consented for publication.

\section{Ethics approval and consent to participate}

Approval from ethics committee was not required. Patient consented for participation.

\section{Funding}

No funding was inflicted.

\section{Publisher's Note}

Springer Nature remains neutral with regard to jurisdictional claims in published maps and institutional affiliations.
Received: 9 August 2017 Accepted: 30 August 2018

Published online: 04 September 2018

\section{References}

1. Tariq S, Hugenberg S, Hirano-Ali S, Tariq H. Multicentric reticulohistiocytosis (MRH): case report with review of literature between 1991 and 2014 with in depth analysis of various regimens and outcomes. Springerplus. 2016;5:180

2. Goltz RM, Laymon CW. Multicentric reticulohistiocytosis of the skin and synovia; reticulohistiocytoma or ganglioneuroma. AMA Arch Dermatol Syphilol. 1954:69(6):717-31.

3. Macia Villa C, Zea-Mendoza A. Multicentric reticulohistiocytosis: case report with response to infliximab and review of treatment options. Clin Rheumatol. 2016:35:527-34.

4. Hiramanek N, Kossard S, Barnetson R. Multicentric reticulohistiocytosis responsive to azathioprine in a patient with no underlying malignancy. Aust J Dermatol. 2002;52:292-4.

5. Trotta F, Castellino G, Lo MA. Multicentric reticulohistiocytosis. Best Prac Res Clin Rheumatol. 2004;18(5):759-72.

6. lannis E, Adamopoulis $\mathrm{P}$, Wordsworth $\mathrm{P}$, et al. Osteoclast differentiation and bone resorption in multicentric reticulohistiocytosis. Hum Pathol. 2006:37:1176-85.
Ready to submit your research? Choose BMC and benefit from

- fast, convenient online submission

- thorough peer review by experienced researchers in your field

- rapid publication on acceptance

- support for research data, including large and complex data types

- gold Open Access which fosters wider collaboration and increased citations

- maximum visibility for your research: over 100M website views per year

At BMC, research is always in progress.

Learn more biomedcentral.com/submissions 